\title{
A virilized patient with congenital hemihypertrophy
}

\author{
S. Mark, O.H. Clark ${ }^{1}$ and R.A. Kaplan
}

Departments of Internal Medicine (Endocrinology), University of California at San Francisco, ${ }^{1}$ Surgery, University of California at San Francisco/Mount Zion, and University of California at Davis, Sacramento, California, USA

\begin{abstract}
Summary: An 18 year old woman with congenital hemihypertrophy of her left side, presented with the rapid onset of virilism, hypertension and a cushingoid appearance. A computed tomographic examination revealed adrenal and hepatic masses. Adrenocortical carcinoma was confirmed by surgical pathology. Hemihypertrophy is linked to a variety of benign and malignant disorders that usually appear during childhood. These disorders include adrenocortical carcinoma and hepatoblastoma. We bring this case to clinical attention to increase awareness that adult patients with congenital hemihypertrophy are still at a significant risk of developing neoplasms.
\end{abstract}

\section{Introduction}

Congenital hemihypertrophy is characterized by enlargement of part of the body in the absence of vascular or neurological disease. ${ }^{1}$ This entity is distinct from the asymmetry found in neurocutaneous disorders and in the Beckwith-Weidemann syndrome, which is associated with exomphalos, macroglossia and gigantism. ${ }^{2}$

Congenital hemihypertrophy was first noted in 1822 by Meckel and in 1839, Wagner recorded the first case. ${ }^{3}$ Since that time, over 230 cases have been reported. ${ }^{4}$ Approximately $4 \%$ of cases are associated with abdominal tumours and urogenital malformations that generally present during childhood. ${ }^{3.4}$ Among these are Wilm's tumours, adrenal malignancies and medullary sponge kidney. To date, 16 cases of adrenocortical carcinoma have been identified with congenital hemihypertrophy. ${ }^{5}$ Herein we report on the seventeenth patient and the oldest with this disorder.

\section{Case report}

The patient is an 18 year old Hispanic female who presented with a 6 month history of hirsutism, a deepened voice and amenorrhea. During an evaluation for atypical chest pain, she was found to be hypertensive and was noted to have a cushingoid appearance. The patient complained of myalgias, polydipsia and odynophagia. On physical examin-

Correspondence: S. Mark, M.D., Metabolic Research Unit, 1143 HSW, University of California, San Francisco, California 94143, USA.

Accepted: 14 February 1994 ation, her blood pressure was $160 / 110 \mathrm{mmHg}$ and her weight was $105 \mathrm{~kg}$. She had moon facies, acne and facial hair. Her physical examination was significant for generalized obesity, hypermuscularity, a few purple abdominal and axillary striae, male pattern escutcheon, clitoromegaly, right axillary fat pad, bilateral supraclavicular fato pads and hemihypertrophy of her left breast, and? left upper and lower extremities.

Findings on laboratory studies included basal morning cortisol $36,000 \mathrm{nmol} / 1$ (normal 138-552 $\mathrm{nmol} / \mathrm{l}$ ), testosterone $17 \mathrm{nmol} / 1$ (normal $1.04-2.43$ $\mathrm{nmol} / \mathrm{l}$ ), 17-hydroxyprogesterone $1.97 \mathrm{nmol} / \mathrm{l}$ (normal $<6.4 \mathrm{nmol} / \mathrm{l}$ ), adrenocorticotrophic hormone $(4 \mathrm{pg} / \mathrm{ml})$ (normal $20-100 \mathrm{pg} / \mathrm{ml}$ ), urinary 17-ketosteroids $227.1 \mu \mathrm{gmol} / \mathrm{day}$ (normal $17-52 \mu \mathrm{gmol} /$ day), deoxycorticosterone $1,600 \mathrm{pmol} / 1$ (normal $130-372 \mathrm{pmol} / \mathrm{l}$ ), oestradiol $245 \mathrm{pmol} / 1$ (normal $73.4-1,835 \mathrm{pmol} / \mathrm{l})$, luteinizing hormone $<0.2 \mathrm{IU} / 1$ (normal 5-25 IU/1), follicle-stimulating hormone $<0.2 \mathrm{IU} / 1$ (normal 4-20 IU/1), thyrotrophin 1.2 $\mathrm{MIU} / 1$ (normal 0.3-5.0 MIU/l), lactate dehydrogenase 1,194 U/1 (normal 105-210 U/1). A computed tomographic (CT) scan of the abdomen revealed an $8 \mathrm{~cm}$ left adrenal mass and a $3 \mathrm{~cm}$ inhomogenous structure in the anterior left lobe of the liver (Figure 1).

The patient underwent an exploratory laparotomy and a left adrenalectomy with partial left hepatectomy without complication. Tumour was present in her left adrenal vein. An intraoperative ultrasound failed to reveal any other liver abnormalities or metastases. Pathological specimens revealed adrenocortical carcinoma with vascular invasion and a solitary metastasis in her liver. Postoperatively, the patient had a transient diuresis 


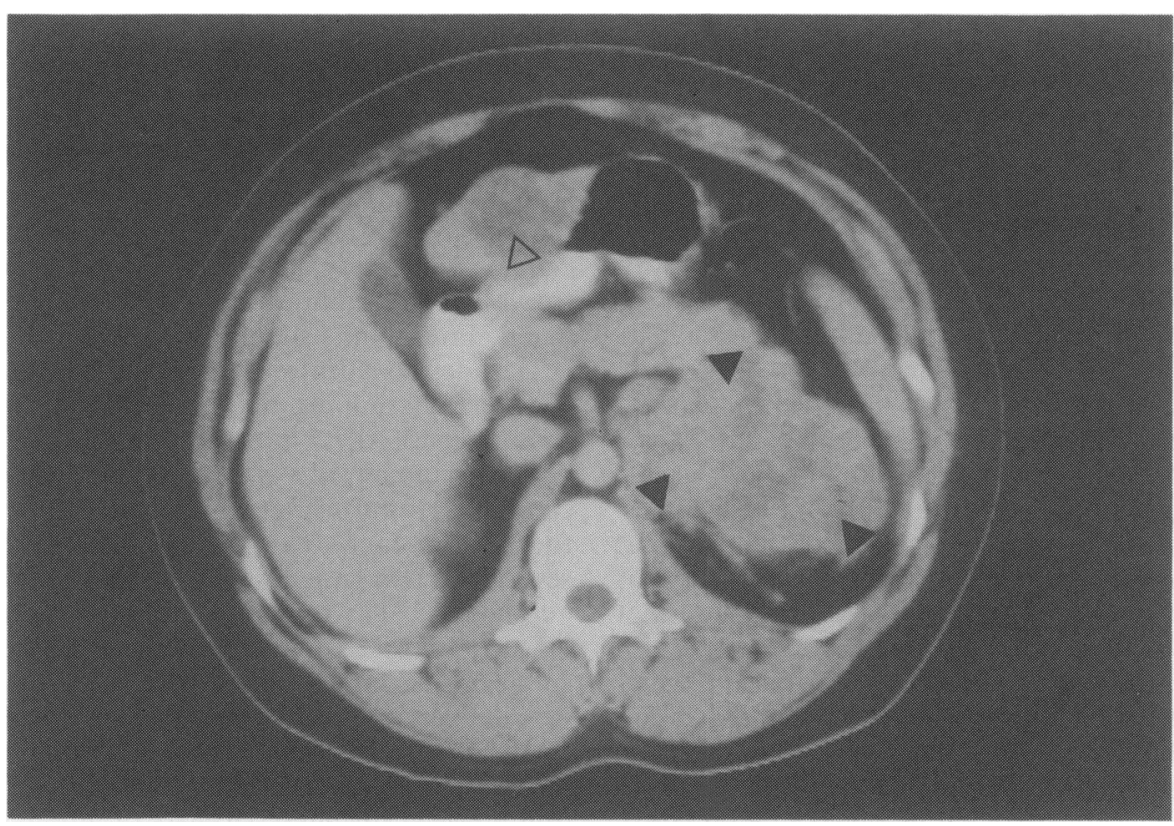

Figure 1 An abdominal CT scan shows an $8 \mathrm{~cm}$ left adrenal mass (closed arrows) and a $3 \mathrm{~cm}$ inhomogenous mass (open arrow) in the anterior left lobe of the liver.

and hyponatraemia. Within several days, she experienced an improvement in her acneiform rash, deepened voice, hypokalaemia and hypertension. The patient was placed on $o, p^{\prime}$-DDD (mitotane). One month after her operation, she had a basal morning cortisol of $2,800 \mathrm{nmol} / 1$ and a 24-hour urinary cortisol of $6,500 \mathrm{nmol} /$ day (normal $27-276 \mathrm{nmol} / \mathrm{D})$. Therapy with $o, p^{\prime}$-DDD was discontinued 2 months after surgery because she experienced severe nausea and vomiting after taking this medication. Six months later, the patient developed malignant pleural effusions and died.

\section{Discussion}

Congenital hemihypertrophy has been thought to be an uncommon disorder. The true incidence of hypertrophy is difficult to determine since minor degrees of asymmetry are considered normal. Gross asymmetry was found in one of every 86,000 hospital records over a 34-year period in the USA. ${ }^{4}$

Hemihypertrophy has been associated with a variety of benign and malignant disorders that usually appear during childhood. ${ }^{3,4}$ It is estimated that $3.8 \%$ of Wilms' tumours, adrenocortical carcinomas and hepatoblastomas have been associated with this disorder. ${ }^{6}$ The mean age of presentation for adrenocortical tumours with hemihypertrophy is 4.6 years. ' Wilms' tumour is the most common neoplasm with approximately 56 reported cases. ${ }^{4}$ Sixteen adrenocortical neoplasms and five hepatoblastomas have also been reported previously. ${ }^{2}$ Medullary sponge kidney, benign nephromegaly, hamartomas and hypospadias are some of the benign lesions described with congenital hemihypertrophy. ${ }^{8-10}$

There have been reports of intra-abdominal neoplasms developing in children with medullary sponge kidney and congenital hemihypertrophy. ${ }^{8}$ Beetz reported that two children, ranging in age from six to nine, had congenital hemihypertrophy, medullary sponge kidney and Wilms' tumours. ${ }^{8}$ Tomooka et al. ${ }^{10}$ reviewed a case in which one child with medullary sponge kidney and hemihypertrophy had developed an adrenal adenoma at the age of 10 .

As this case demonstrates, there does not appear to be a relationship between the degree of asymmetry and the occurrence of abdominal disease. ${ }^{11}$ Furthermore, there does not appear to be a relationship between the side of the hypertrophy and the side of the tumour. ${ }^{1}$ Adrenal tumours associated with congenital hemihypertrophy usually arise in the cortex. ${ }^{11}$ Functioning adrenocortical tumours were more common in female patients with a female to male ratio of $3: 1 .^{11}$

Sexual precocity, Cushing's syndrome or virilism as determined by elevated urinary 17-ketosteroids is usually the presenting feature. ${ }^{4}$ Haiken per- 
formed an intravenous pyelogram in an asymptomatic patient with hemihypertrophy at the age of 10 months and found localized adrenocortical carcinoma. ${ }^{12}$ The patient had no evidence of disease for at least one year after surgical resection. Unfortunately, by the time a patient presents with signs or symptoms, the malignancy may have metastasized. Therefore, close surveillance with ultrasound or computed tomography is advocated. ${ }^{1.5 .8 .12}$ Since five cases of adrenocortical carcinoma with congenital hemihypertrophy were reported before one year of age, and the earliest reported presentation for adrenocortical carcinoma was in a 8 month old infant, ${ }^{5}$ baseline screening may be necessary before one year of age.

For many years, researchers postulated that mutational defects may be responsible for this entity. Knudson and Strong have postulated that two randomly occurring events are necessary in tumour formation. ${ }^{2}$ This concept has been further explored and it now appears that an aberration within the p53 tumour suppressor gene, which is the most frequently identified genetic error in human cancer, may be involved. ${ }^{13}$ Regulatory functions proposed for the p53 protein include modulation of the cell cycle, cellular differentiation, signal transduction, gene expression and protection against incorporation of damaged DNA. ${ }^{13.14}$

Germline p53 mutations appear to be inherited among the members of families with the rare autosomal dominant susceptibility to cancer, the Li-Fraumeni syndrome. ${ }^{15}$ Patients generally present with malignancy under the age of 40 . Hartley presented the epidemiological data on 14 cases of adrenal cortical tumours that were registered with the Manchester Children's Tumour Registry from 1954 to $1985 .{ }^{16} \mathrm{He}$ found that four of the children could be members of families with the SBLA (sarcoma, breast and brain tumours, leukaemia, laryngeal and lung cancer and adrenocortical carcinoma) cancer family syndrome or otherwise known as the Li-Fraumeni syndrome. Of the four,

\section{References}

1. Pfister, R.C., Weber, A.L., Smith, E.H., Wilkinson, R.H. \& May, D.A. Congenital asymmetry (hemihypertrophy) and abdominal disease. Radiology 1975, 116: 685-691.

2. Knudson, A.G. \& Strong, L.C. Mutation of cancer: a model for Wilms' tumor of the kidney. J Natl Cancer Inst 1972, 48: 313-324.

3. Saypol, D.C. \& Laudone, V.P. Congenital hemihypertrophy with adrenal carcinoma and medullary sponge kidney. Urology 1983, 21: 510-511.

4. Parker, D.A. \& Skalko, R.G. Congenital asymmetry: report of 10 cases with associated developmental abnormalities. Pediatrics 1969, 44: 584-589.

5. Ogita, S., Takiwa, K., Takahashi, T., Kinugasa, A. \& Sawada, T. Adrenocortical carcinoma in a child with congenital hemihypertrophy. $Z$ Kinderchirurgie 1989, 44: 166-168. one child had congenital hemihypertrophy and a left adrenal adenoma. The mother of this child had anomalies of the renal tract and two grandparents had died from urogenital malignancies. No other family members had congenital hemihypertrophy. Although conclusions were not established about the possible patterns of inheritance for this syndrome, which may include congenital hemihypertrophy, an association with a wide range of germline p53 mutations should be considered.

Despite the recent progress that has been made towards determining the genetic defect linked to tumorigenesis, the results of therapy for adrenocortical carcinoma are poor. Adrenocortical carcinoma is a rare malignant tumour that accounts for $0.2 \%$ of cancer deaths. ${ }^{17}$ Schteingart reviewed several series of patients who received treatment for adrenocortical carcinoma. He found that $o, p^{\prime}$ DDD therapy that was started shortly after the surgical excision and before local extension of the development of distant metastases increased mean survival from 10.3 months to 74 months. ${ }^{17}$ There have not been any reports suggesting an association between the aggressiveness of adrenal cancer and congenital hemihypertrophy. ${ }^{11}$

Since there is an increased frequency of potentially lethal diseases such as adrenocortical carcinoma and hepatoblastoma, it now appears essential that patients with congenital hemihypertrophy be closely followed even throughout adulthood. Frequent physical examinations are an important part of patient management. Based on our experiences and reported cases, we recommend that annual ultrasound or abdominal computed tomography be included in these evaluations for an indefinite period of time. Perhaps in the future, genetic screening for germline mutations in the affected patient may be a part of the evaluation. It is important for the general practitioner to be aware of the association between malignancy and hemihypertrophy since early diagnosis and treatment may enhance survival.

6. Groff, D.B. \& Buchino, J.J. A child with hemihypertrophy and a right flank mass. $J$ Pediatr 1982, 100: 500-504.

7. Neblett, W.W., Frexes-Steed, M. \& Scott, H.W. Experience with adrenocortical neoplasms in childhood. Am Surg 1987, 53: $117-125$.

8. Beetz, R., Schofer, O., Riedmiller, H., Schumacher, R. \& Gutjahr, P. Medullary sponge kidneys and unilateral Wilms tumour in a child with Beckwith Wiedemann syndrome. Eur J Pediatr 1991, 150: 489-492.

9. Harris, R.E., Fuchs, E.F. \& Kaempf, M.J. Medullary sponge kidney and congenital hemihypertrophy: case report and literature review. J Urol 1981, 126: 676-678.

10. Tomooka, Y., Onitsuka, H. \& Goya, M.D. Congenital hemihypertrophy with adrenal adenoma and medullary sponge kidney. Br J Radiol 1988, 61: 851-853. 
11. Lee, P.D., Winter, R.J. \& Green, O.C. Virilizing adrenocortical tumors in childhood: eight cases and a review of the literature. Pediatrics 1985, 76: 437-444.

12. Haicken, B.N., Schulman, N.H. \& Schneider, K.M. Adrenocortical carcinoma and congenital hemihypertrophy. J Pediatr 1973, 83: 284-285.

13. Hulla, J.E. \& Schneider, R.P. Structure of the rat p53 tumor suppressor gene. Nucl Acid Res 1993, 21: 713-717.

14. Malkin, D. \& Friend, S.H. Correction: a Li-Fraumeni syndrome p53 mutation. Science 1993, 259: 878.
15. Sameshima, Y., Tsunematsu, Y., Watanabe, S. et al Detection of novel germ-line p 53 mutations in diverse cancer-prone families identified by selecting patients with childhood adrenocortical carcinomas. J Natl Cancer Inst 1992, 84: 703-707.

16. Hartley, A.L., Birch, J.M, Marsden, H.B., Reid, H., Harris, M. \& Blair, V. Adrenal cortical tumours: epidemiological and familial aspects. Arch Dis Child 1987, 62: 683-689.

17. Schteingart, D.E. Treating adrenal cancer. Endocrinologist 1992, 2: 149-157. 